\title{
Eculizumab in paroxysmal nocturnal hemoglobinuria with Budd-Chiari syndrome progressing despite anticoagulation
}

Andrés Brodsky ${ }^{1 *}$, Octavio Mazzocchi ${ }^{2}$, Fabiana Sánchez ${ }^{3}$, Gus Khursigara ${ }^{4}$, Suneil Malhotra ${ }^{4}$ and Mariano Volpacchio ${ }^{3}$

\begin{abstract}
Paroxysmal nocturnal hemoglobinuria (PNH) is a progressive, life-threatening disorder characterized by chronic intravascular hemolysis caused by uncontrolled complement activation. Hepatic vein thrombosis (Budd-Chiari syndrome) is common in PNH patients. This case report describes the response to eculizumab (a humanized monoclonal antibody that inhibits terminal complement activation) in a 25-year-old male with progressive liver function deterioration despite standard anticoagulation therapy and transjugular intrahepatic porto-systemic shunt. The patient presented with anemia, severe thrombocytopenia, headache, abdominal pain, and distention. He was diagnosed with PNH, cerebral vein thrombosis, and Budd-Chiari syndrome. Despite adequate anticoagulation, diuretic administration, and placement of a transjugular shunt, additional thrombotic events and progressive liver damage were observed. Eculizumab therapy was initiated, resulting in rapid blockade of intravascular hemolysis, increased platelet counts, ascites resolution, and liver function recovery, all of which are presently sustained. Since starting eculizumab the patient has had no further thrombotic events and his quality of life has dramatically improved. This is the first report to confirm the role of complement-mediated injury in the progression of Budd-Chiari syndrome in a patient with $\mathrm{PNH}$. This case shows that terminal complement blockade with eculizumab can reverse progressive thromboses and hepatic failure that is unresponsive to anticoagulation therapy and suggests that early initiation of eculizumab should be included in the therapeutic regimen of patients with PNH-related Budd-Chiari syndrome.
\end{abstract}

Keywords: Budd-Chiari syndrome, Complement inhibition, Eculizumab, Paroxysmal nocturnal hemoglobinuria

\section{Background}

Paroxysmal nocturnal hemoglobinuria $(\mathrm{PNH})$ is a lifethreatening, progressive, acquired genetic disease characterized by the clonal, nonmalignant expansion of hematopoietic stem cells deficient in glycosylphosphatidylinositol (GPI) synthesis. This deficiency results in fewer GPI-anchored complement inhibitors (CD55 and CD59) on the cell surface, causing increased chronic complement-mediated intravascular hemolysis and platelet hyperactivation and aggregation [1]. Both processes lead to an increased risk of thrombosis, renal dysfunction and damage, pulmonary hypertension, and

\footnotetext{
* Correspondence: albrodsky01@yahoo.com.ar

'División Hematología, Hospital de Clínicas "José de San Martin", Av. Córdoba 2351 (C1120AAR) Ciudad Autónoma de Buenos Aires, 5950-8000 Argentina Full list of author information is available at the end of the article
}

anemia, which, despite historical treatment regimens, have resulted in up to $35 \%$ mortality within 5 years of diagnosis [2]. Thromboembolism is the most common cause of PNH-related death, accounting for two-thirds of all mortalities in patients with this disease [3]. Between $29 \%$ and $44 \%$ of PNH patients experience a clinically evident thromboembolism, affecting the liver, brain, gut, and kidney $[3,4]$. Recent registry analyses support an 8.4- to 15.4-fold increased risk of death in patients with PNH with thromboembolism $[4,5]$.

Budd-Chiari syndrome (BCS) is common in $\mathrm{PNH}$ patients and anticoagulation therapy is traditionally the first treatment choice for the management of this disorder. However, PNH patients frequently experience new thrombotic episodes despite adequate anticoagulation, which limits the usefulness of subsequent hepatic vein angioplasty and/or stenting and transjugular intrahepatic porto-

\section{Biomed Central}


systemic shunt (TIPS) placement $[3,6,7]$. Further complicating anticoagulation management, thrombocytopenia occurs in $25 \%$ to $52 \%$ of $\mathrm{PNH}$ patients, creating a high risk of severe bleeding [5,8]. Additional therapeutic options for BCS in patients with PNH are limited to high-risk allogeneic hematopoietic stem-cell transplantation or liver transplantation. In one retrospective study in patients with $\mathrm{PNH}$, there was a $22 \%$ reduction in 5-year survival in patients who had received stem-cell transplantation compared with those who had not [9] while liver transplantation in patients with ongoing intravascular hemolysis due to PNH has been associated with high rates of thrombotic and hemorrhagic complications [10].

Eculizumab is a humanized monoclonal antibody that specifically targets the terminal complement protein $\mathrm{C} 5$, blocking complement-mediated hemolysis. Two multinational, phase 3 studies and a related extension study demonstrated that eculizumab significantly reduces hemolysis and thrombotic events in patients with $\mathrm{PNH}$ $[3,11,12]$. These studies also showed that eculizumab was effective in reducing renal impairment, pulmonary hypertension, and transfusion requirements, while improving fatigue and quality of life. Furthermore, longterm treatment with eculizumab has been shown to normalize survival of patients with PNH compared with age- and sex-matched controls [6]. Long-term treatment with eculizumab has demonstrated a favorable safety profile [3,11-13].

Here, we describe the effect of eculizumab in a patient with $\mathrm{PNH}$ who was being considered for liver transplantation because of multiple thrombotic events, progressive BCS, and declining liver function.

\section{Case report}

In June 2005, a 25-year-old white male was hospitalized when he presented with progressive headache, emesis, abdominal pain, and abdominal distension. Ascites was diagnosed and $2500 \mathrm{~mL}$ serous liquid was drained via paracentesis. Physical examination revealed hepatomegaly, splenomegaly, and bilateral papilloedema. Blood analysis showed a hemoglobin concentration of $9 \mathrm{~g} / \mathrm{dL}$ (normal range: 14-18 g/dL), white blood cell count of $3.3 \times 10^{9} / \mathrm{L}$ (normal range: $4.3-10.8 \times 10^{9} / \mathrm{L}$ ), platelet count of $19 \times 10^{9} / \mathrm{L}$ (normal range: $150-400 \times 10^{9} / \mathrm{L}$ ), unbound bilirubin concentration of $1.7 \mathrm{mg} / \mathrm{dL}$ (normal range: $0.2-0.8 \mathrm{mg} / \mathrm{dL}$ ), and lactate dehydrogenase (LDH) levels of $1684 \mathrm{U} / \mathrm{L}$ (upper limit of normal: $480 \mathrm{U} / \mathrm{L}$ ). Both Ham and sucrose tests were positive and peripheral blood flow cytometry confirmed the diagnosis of $\mathrm{PNH}$ with a granulocyte clone size of $95 \%$. Magnetic resonance imaging (MRI) scans showed BCS (Figure 1) and magnetic resonance angiography (MRA) identified thromboses of the left transverse and superior sagittal cerebral sinus veins (Figure 2).

Despite severe thrombocytopenia, the patient received anticoagulation therapy in the form of subcutaneous enoxaparin ( $1 \mathrm{mg} / \mathrm{kg}$ every 12 hours) for 80 months. The patient also received supplemental oral iron and folic acid and was treated with a short course of corticosteroids (methylprednisone, $1 \mathrm{mg} / \mathrm{kg} /$ day) to improve thrombocytopenia. In spite of adequate parenteral anticoagulation, BCS progressed and the patient experienced two symptomatic suprahepatic thromboses, increasingly refractory ascites, and painful congestive hepatomegaly, requiring the placement of a TIPS, an immediate splenic embolization (Figure 3), and an additional course of corticosteroids to treat severe refractory thrombocytopenia. A TIPS thrombosis developed and endovascular repermeabilization was required to restore TIPS patency succesfully. A second definitive TIPS thrombosis soon ensued, which was followed by refractory ascites that required paracentesis every 2 to 3 weeks, progressive
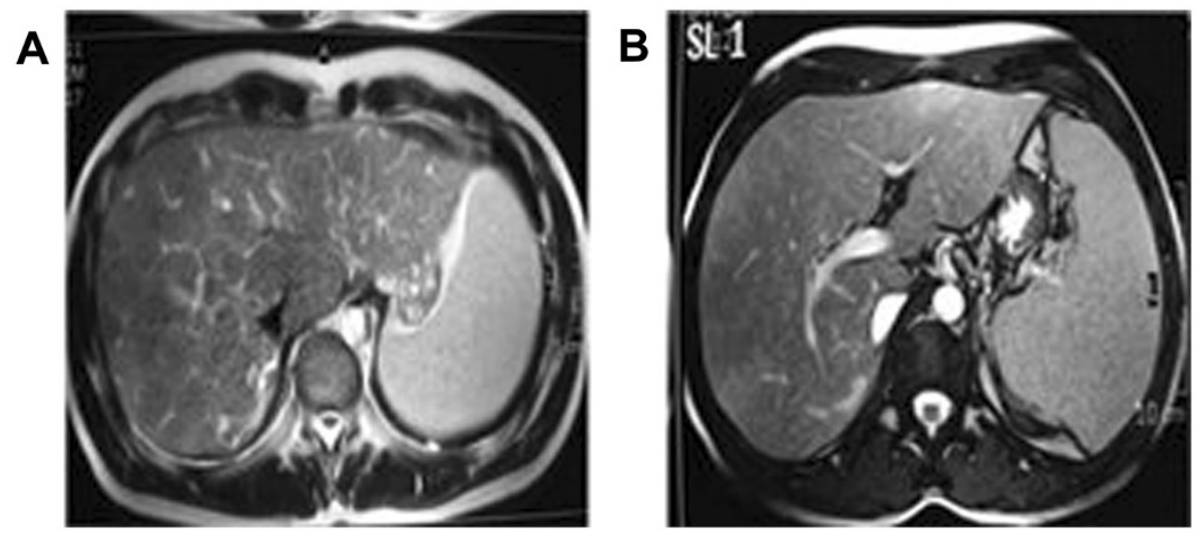

Figure 1 MRI evidence of BCS. (A) $T_{2}$-weighted MRI. Hepatic veins are not identified. Notice presence of comma-shaped intrahepatic collateral vessels. (B) Image obtained caudal to (A) shows a normal appearing portal vein. 

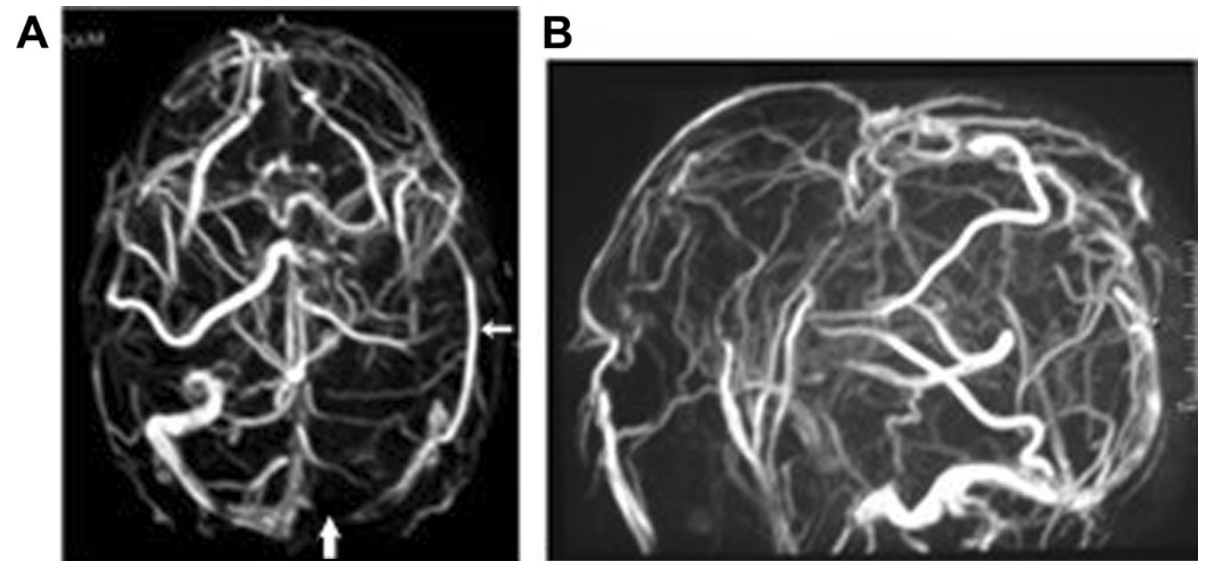

Figure 2 MRA evidence of cerebral vein thrombosis. (A) A complete thrombotic occlusion of the left transverse sinus vein origin is evident (thick arrow). Collateral circulation (thin arrow) partially fills its proximal portion. (B) Partial thrombotic occlusion of the superior sagittal sinus vein.

liver damage (resulting in consideration for liver transplantation), and two episodes of symptomatic pulmonary embolism (Figure 4).

Neither anticoagulation nor TIPS placement prevented further thromboembolisms-the patient experienced two hepatic thromboses and two pulmonary embolisms over more than 40 months of therapy-that increased the extent of liver damage. Therefore, alternative treatment to prevent complement-mediated thrombosis was explored.

In January 2009, eculizumab (Alexion Pharmaceuticals, Cheshire, CT) treatment was initiated at the approved dosing regimen: $600 \mathrm{mg}$ weekly for the first 4 weeks, followed by $900 \mathrm{mg}$ for the fifth dose 1 week later, then $900 \mathrm{mg}$ every

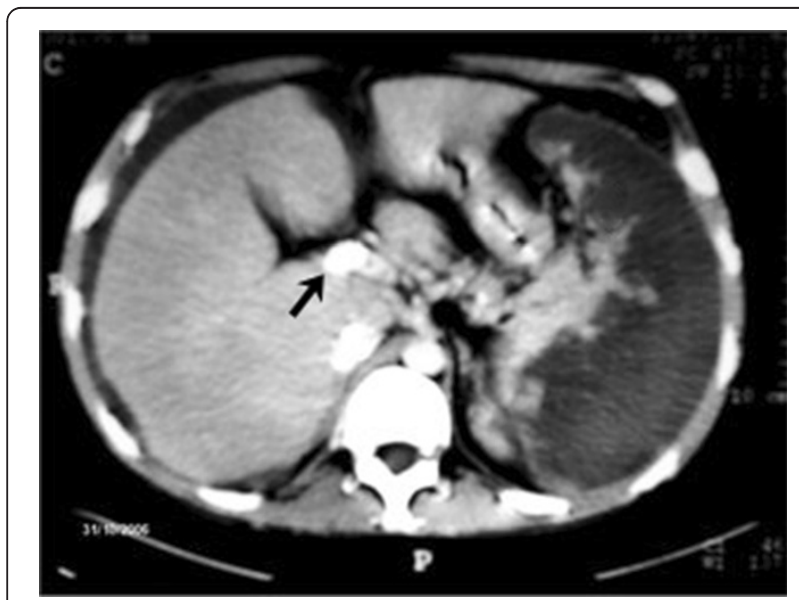

Figure 3 Abdominal computed tomography scan showing a transjugular intrahepatic portosystemic shunt (arrow) and a massive splenic infarct as a result of the splenic embolization.
2 weeks thereafter. Within 2 weeks of starting treatment with eculizumab, LDH levels had decreased by $73 \%$ from an average of 2.9-fold above normal 1 to 2 months before treatment to within normal levels $(\leq 480 \mathrm{U} / \mathrm{L})$. This reduction was maintained for more than 2.5 years (921 days; Table 1), the latest data collected for this patient. Platelet count increased from $23 \times 10^{9} / \mathrm{L}$ on day 1 of eculizumab treatment to $53 \times 10^{9} / \mathrm{L}$, a $130 \%$ increase, after 1 week and was sustained at a level of between 53 and $94 \times 10^{9} / \mathrm{L}$ (average $67 \times 10^{9} / \mathrm{L}$ ) for 921 days. Rapid improvements in hepatic function were also observed, with alanine aminotransferase and aspartate aminotransferase levels reduced by $68.3 \%$ and $76.9 \%$, respectively, from assessments

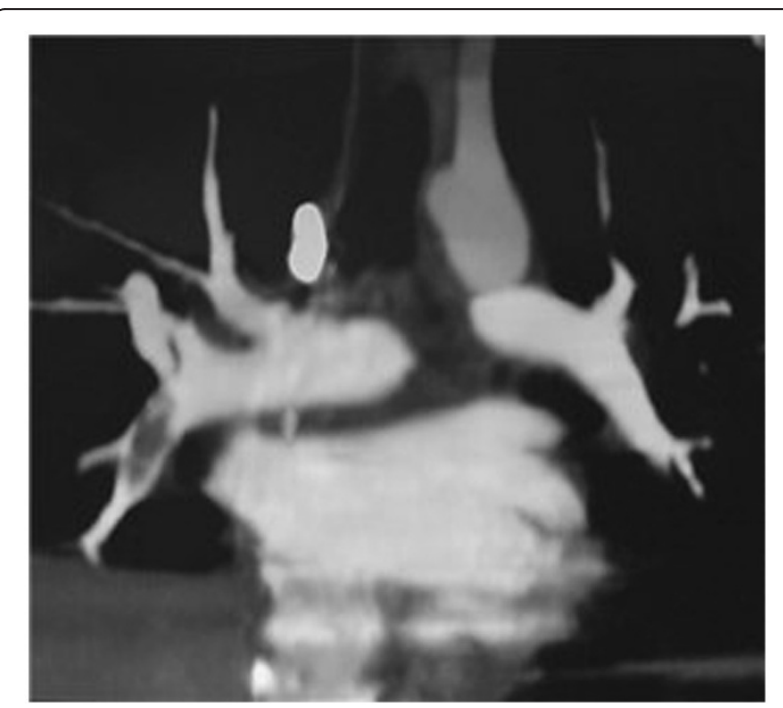

Figure $\mathbf{4}$ Coronal reconstruction of a pulmonary computed tomography angiography. An embolus is seen in the lower right lung artery. 
Table 1 Effect of eculizumab on liver function

\begin{tabular}{|c|c|c|c|c|c|c|c|c|c|}
\hline \multirow{3}{*}{$\begin{array}{l}\text { Days post- } \\
\text { eculizumab }\end{array}$} & \multicolumn{9}{|c|}{ Laboratory value (normal range) } \\
\hline & LDH & Platelets & Hemoglobin & AST & ALT & Bilirubin total & Bilirubin D & Cholinesterase & Albumin \\
\hline & $\begin{array}{c}\mathrm{U} / \mathrm{L} \\
(\leq 480)\end{array}$ & $\begin{array}{c}\times 10^{9} / \mathrm{L} \\
(150-400)\end{array}$ & $\begin{array}{c}\mathrm{g} / \mathrm{dL} \\
(14-18)\end{array}$ & $\begin{array}{c}\overline{U / L} \\
(\leq 40)\end{array}$ & $\begin{array}{c}\overline{U / L} \\
(\leq 37)\end{array}$ & $\begin{array}{c}\mathrm{mg} / \mathrm{dL} \\
(0.2-1.3)\end{array}$ & $\underset{(<0.3)}{\mathrm{mg} / \mathrm{dL}}$ & $\begin{array}{c}\mathrm{U} / \mathrm{L} \\
(>4400)\end{array}$ & $\begin{array}{c}\mathrm{g} / \mathrm{dL} \\
(3.5-5.0)\end{array}$ \\
\hline-68 & 1836 & 34 & 9.2 & 63 & 78 & 3.6 & 1.7 & 3572 & - \\
\hline-33 & 921 & 27 & 9.8 & 49 & 70 & 2.4 & 0.9 & 2889 & 3.47 \\
\hline 0 (1st dose) & - & 23 & 10.7 & 36 & 24 & 3.3 & 1.4 & - & - \\
\hline 7 & 519 & 53 & 9.7 & 20 & 18 & 2.3 & 1 & - & 3.54 \\
\hline 14 & 368 & 57 & 10.3 & 15 & 14 & 1.9 & 0.7 & - & - \\
\hline 56 & 565 & 80 & 9.6 & 28 & 9 & 2.2 & 1 & 5135 & 3.6 \\
\hline 119 & 248 & 53 & 9.9 & 16 & 8 & 1.7 & 0.8 & 5975 & - \\
\hline 202 & 295 & 94 & 11.3 & 25 & 20 & 2.1 & 0.9 & 6968 & 4.52 \\
\hline 300 & 344 & 62 & 10.3 & 28 & 25 & 1.6 & 0.6 & 7603 & 4.68 \\
\hline 365 & 298 & 58 & 10.2 & 22 & 19 & 1.6 & 0.7 & - & 4.27 \\
\hline 449 & 354 & 69 & 11.3 & 26 & 26 & 1.9 & 0.8 & 7704 & 5.1 \\
\hline 547 & 340 & 63 & 12 & 25 & 24 & 1.6 & 0.6 & 7852 & 4.73 \\
\hline 631 & 285 & 73 & 11.6 & 26 & 27 & 1.8 & 0.7 & 8360 & - \\
\hline 743 & 351 & 65 & 11.5 & 26 & 23 & 1.7 & 0.7 & 8294 & 4.46 \\
\hline 827 & 388 & 64 & 11.2 & 26 & 22 & 1.4 & 0.6 & - & - \\
\hline 921 & 423 & 77 & 12.6 & 28 & 25 & 1.9 & 0.6 & - & 4.49 \\
\hline
\end{tabular}

$A L T$, alanine aminotransferase; $A S T$, aspartate aminotransferase.

made 68 days prior to treatment initiation to after 1 week of eculizumab therapy (Table 1). The significant reductions in both of these enzymes were sustained over the 921-day treatment time frame reported in this case study. Over the same period, total bilirubin level declined by between $36.1 \%$ and $61.1 \%$. The concentration of cholinesterase, a marker of liver function, improved to within the normal level within 56 days of treatment initiation, the earliest time at which this parameter was measured, with a progressive increase thereafter, which is a clear sign of ongoing hepatic functional recovery. Changes in albumin levels paralleled those for cholinesterase and are representative of improvements in the synthetic capacity of the liver.

The interval between paracentesis increased progressively, giving a clear indication of a decrease in portal hypertension. After 7.5 months of eculizumab treatment, no further ascitic fluid evacuation was required. Diuretics, beta blockers, and hydrosaline restriction were also stopped after 2 years of eculizumab treatment. Serial liver MRA studies showed abundant intrahepatic venous collateral circulation without recanalization of the hepatic veins (Figure 5), and development of portal cavernomatosis (evidence of portal vein thrombosis, which appeared after TIPS thrombosis; Figure 5), paralleled the progressive improvement in liver function and hemodynamics. An ultrasound study showed a partial recanalization of the suprahepatic veins, which was unnoticed in MRA studies due to the low blood flow in the recovered blood vessels
(Figure 6). In parallel with the improvement in liver vein thrombosis, a near-complete recanalization of the cerebral left transverse venous sinus, as well as partial recanalization of the sagittal vein sinus, also took place (Figure 7). As a consequence of these improvements, plans for liver transplantation were rescinded.

Following initiation of eculizumab, the patient experienced no new symptomatic thrombotic episodes, had a dramatic improvement in fatigue, and did not experience any clinically significant treatment-related adverse events. Consequently, the patient was able to resume a near-normal work and social life.

\section{Discussion}

This is the first report to confirm the role of complementmediated injury in the progression of BCS in a patient with $\mathrm{PNH}$ and its improvement with eculizumab treatment.

Thromboembolism is the most common cause of PNH-related death, accounting for two-thirds of all mortalities in patients with this disease [3]. Between 29\% and $44 \%$ of PNH patients experience a clinically evident thromboembolism, which affects the liver, brain, gut and kidney $[3,4]$. This patient was no exception as he developed 2 hepatic and 2 pulmonary thromboembolisms, despite 40 months of anticoagulation and TIPS therapy. Recent registry analyses support an 8.4- to 15.4-fold increased risk of death in patients with $\mathrm{PNH}$ with thromboembolism $[4,5]$. Historically, this increased risk 


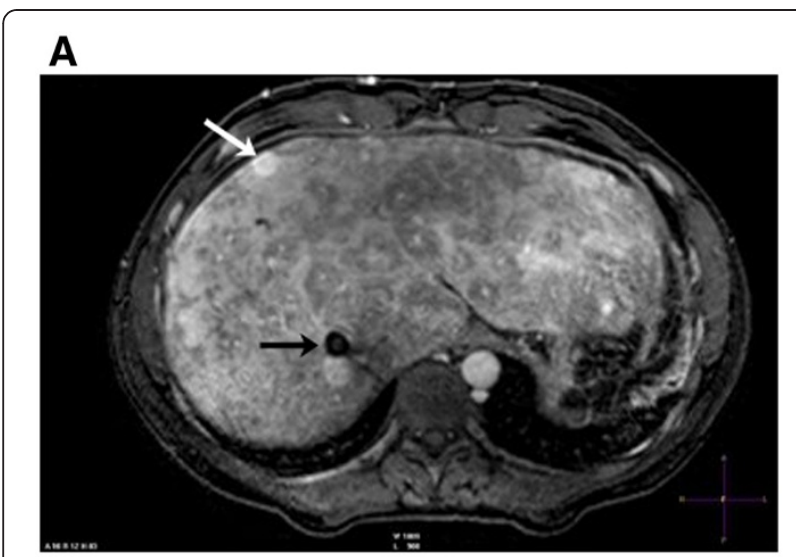

B

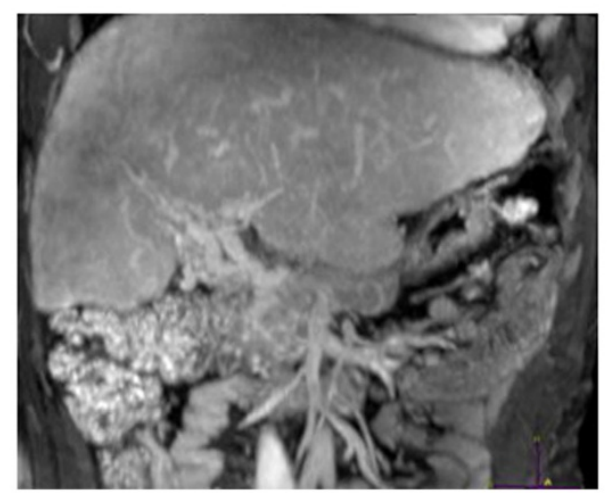

Figure $\mathbf{5}$ Contrast-enhanced $\mathbf{T}_{\mathbf{1}}$-weighted MRI. (A) The axial view shows morphological changes and heterogeneous enhancement typical of BCS. A hypervascular nodule is seen consistent with a regenerative nodule (white arrow). A TIPS also is seen (black arrow). Notice collateral circulation in the abdominal wall. (B) The coronal view shows prominent tortuous vascular structures compatible with cavernomatous transformation of the portal vein.

of thrombosis, along with other life-threatening complications such as chronic kidney disease, pulmonary hypertension and anemia, have resulted in up to $35 \%$ of patients with $\mathrm{PNH}$ dying within 5 years of diagnosis [2].

The patient is currently receiving eculizumab and since starting this therapy has not experienced any new thromboses. This is consistent with recent large cohort analyses in the United Kingdom that show that anticoagulation for primary antithrombotic prophylaxis can be safely discontinued in some patients with PNH who are concurrently receiving eculizumab [6].

Hepatic dysfunction and deterioration in patients with PNH may also result, in part, from increased vascular resistance and/or inflammation, as reported in renal and pulmonary systems $[14,15]$. For example, chronic complement activation in PNH can lead to local damage of hepatic and/ or Kupffer cells, subsequent upregulation of adhesion molecules, and release of proinflammatory cytokines, such as interleukin-1 and -6 [16,17]. In addition, complementmediated depletion of the smooth muscle relaxant nitric oxide has been linked to pulmonary and systemic hypertension [15,18], as well as reduction of renal blood flow and function [14]. These effects are ameliorated by the inhibition of terminal complement activation by eculizumab, which improves chronic kidney disease in patients with $\mathrm{PNH}$ as early as 12 weeks post-treatment [14] and reduces the risk of systemic and pulmonary hypertension [15]. Thus, it is reasonable to suggest that terminal complement inhibition, besides blocking thrombosis in $\mathrm{PNH}$, may prevent vasoconstriction and inflammation that affects both hepatic flow and liver function in PNH patients with BCS. In addition, patients with $\mathrm{PNH}$ who are thrombocytopenic, including the patient in this case, are at higher risk of thromboembolism than $\mathrm{PNH}$ patients with normal platelet levels [19]. Eculizumab-mediated improvement of platelet count reduces the risk of thromboembolism, and may increase the safety of concomitant anticoagulation and/or subsequent treatment modalities, including allogeneic hematopoietic stem-cell transplantation or liver transplantation.

In this case, the patient responded to eculizumab with a dramatic restoration of hepatic function. The retraction of a planned liver transplant highlights the remarkable improvements that this patient experienced, and bodes well for future $\mathrm{PNH}$ cases with similar symptom presentations.

Eculizumab represents the first treatment for $\mathrm{PNH}$ that effectively inhibits complement-mediated intravascular hemolysis and prevents subsequent morbidities, including thromboembolism, renal dysfunction, hypertension, and poor quality of life. Based on the successful treatment of this patient with $\mathrm{PNH}$ and $\mathrm{BCS}$, together with the antithrombotic and also the antihypertensive and antiinflammatory benefits of inhibiting terminal complement activation, we suggest that the treatment algorithm proposed by Hoekstra et al. [20] should be modified to include terminal complement inhibition with eculizumab as a primary therapeutic intervention in $\mathrm{PNH}$ patients who present with BCS (Figure 8).

\section{Conclusions}

Eculizumab, a humanized monoclonal antibody that targets the C5 complement protein, is effective at blocking complement-mediated hemolysis in $\mathrm{PNH}$ patients. The ability of eculizumab to reverse the damaging effects of BCS confirms the role of complement in the progression of this disease in PNH patients. The absence of new thromboses in this patient after receiving eculizumab supports the application of eculizumab in the treatment of $\mathrm{PNH}$ patients with $\mathrm{BCS}$.

\section{Consent}

Written informed consent was obtained from the patient for publication of this case report and any accompanying images. 


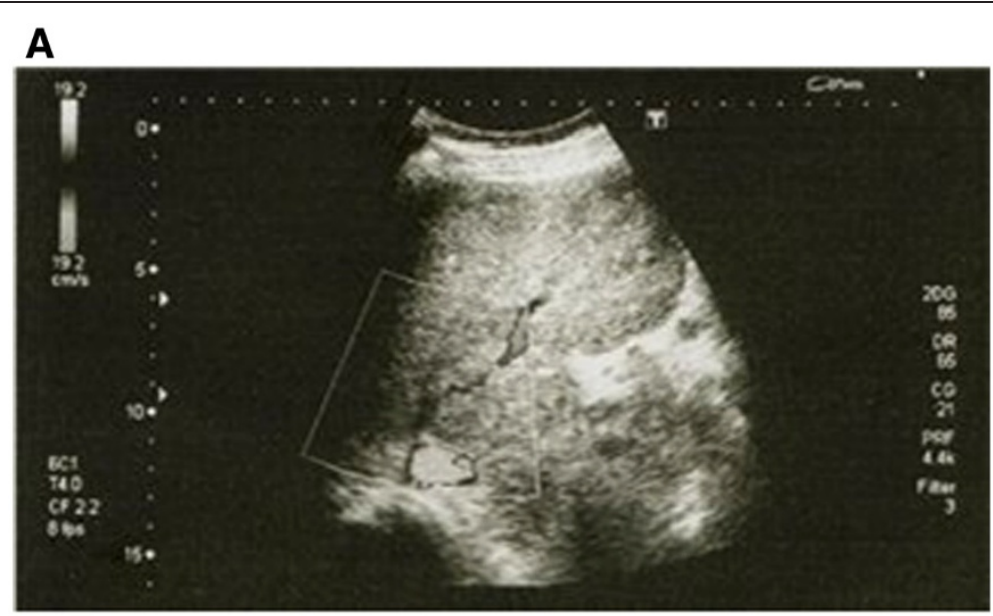

\section{B}

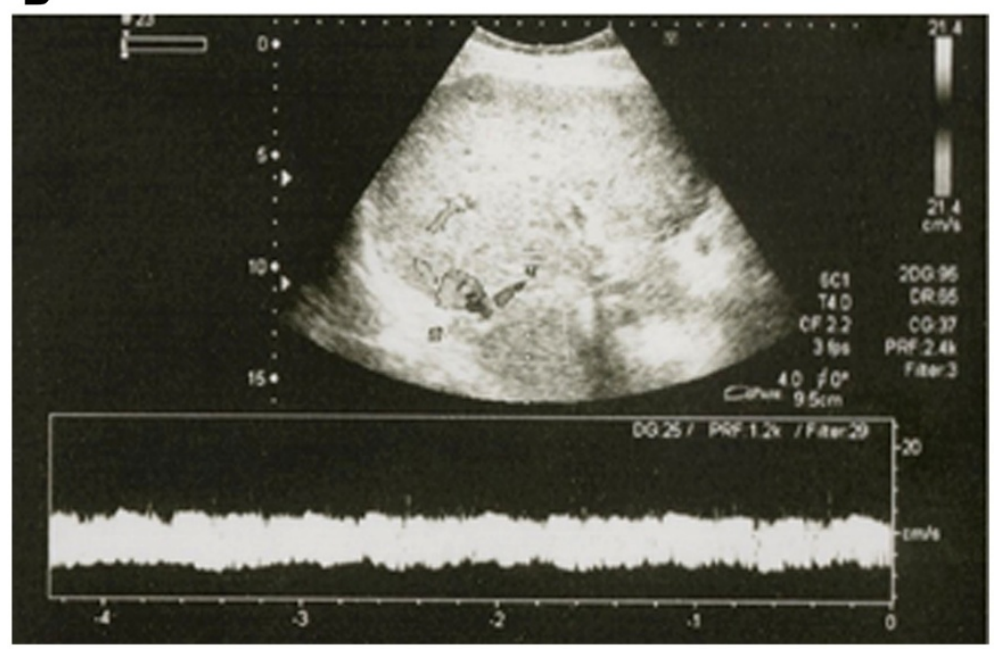

Figure 6 Sonographic images showing improved hepatic venous flow. (A) Ultrasonographic detection of partial recanalization of the right suprahepatic vein ("narrow pass image"). (B) Ultrasound Doppler evaluation of the right suprahepatic vein showing a continuous flow instead of a pulsatile signal. This is due to a proximal partial obstruction of the hepatic venous outflow.
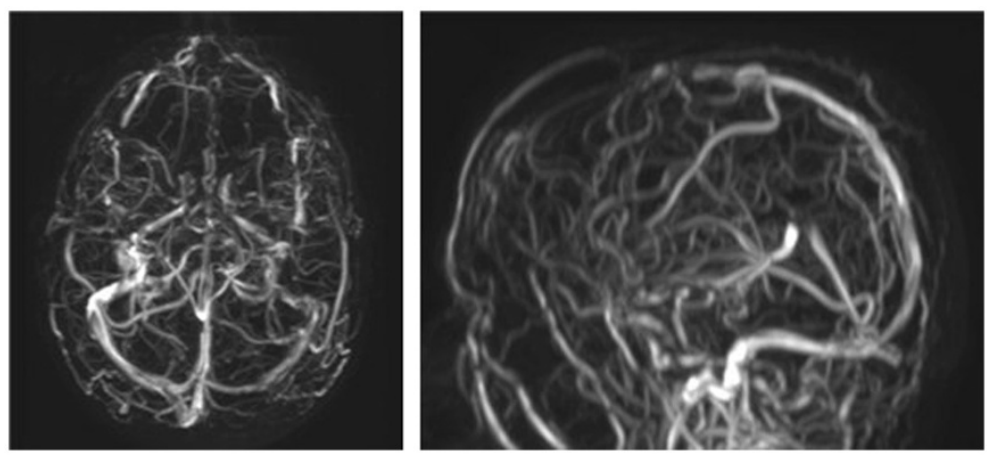

Figure 7 Axial and sagittal venous MRA show resolution of left transverse sinus occlusion and partial resolution of sagittal venous sinus thrombosis. 


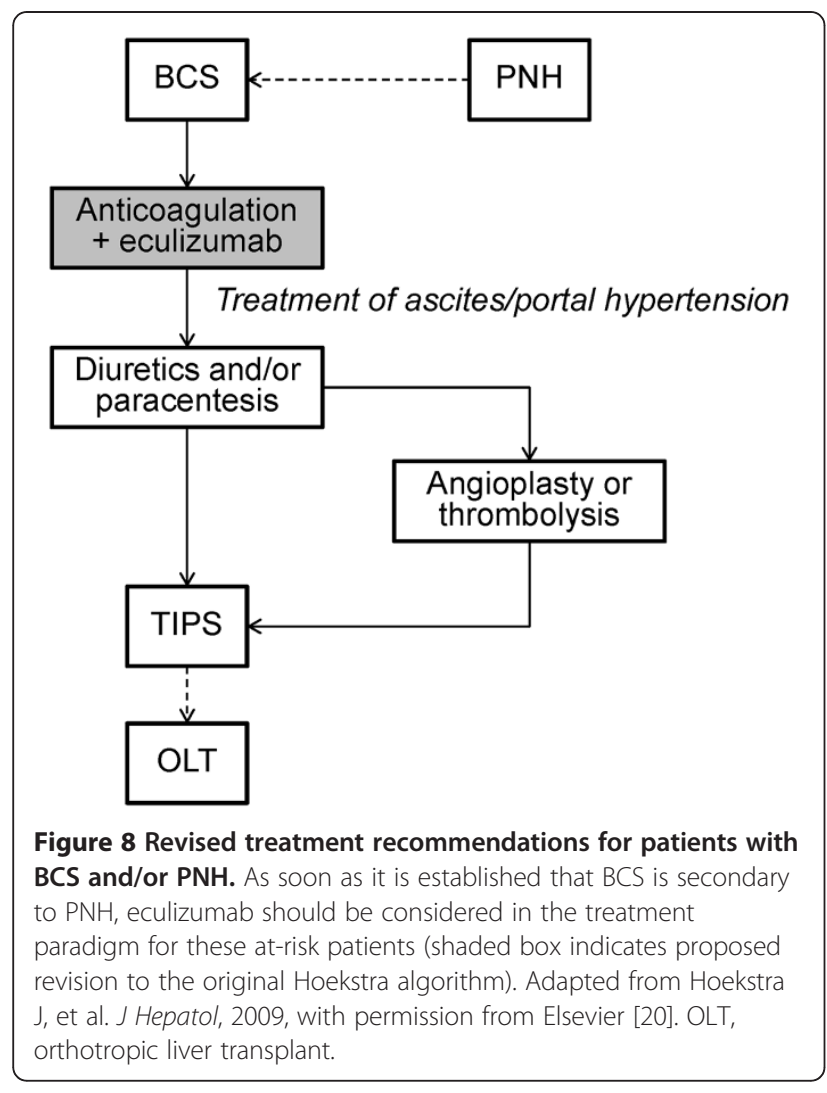

\begin{abstract}
Abbreviations
PNH: Paroxysmal nocturnal hemoglobinuria;

GPI: Glycosylphosphatidylinositol; BCS: Budd-Chiari syndrome;

TIPS: Transjugular intrahepatic porto-systemic shunt; LDH: Lactate dehydrogenase; MRI: Magnetic resonance imaging; MRA: Magnetic resonance angiography.
\end{abstract}

\section{Competing interests}

Andrés L. Brodsky: consultancy and speakers bureau for Alexion Pharmaceuticals, Inc. Octavio Mazzocchi: none to declare. Fabiana Sanchez: none to declare. Gus Khursigara: employed by Alexion Pharmaceuticals, Inc., and owns equity in the company. Suneil Malhotra: employed by Alexion Pharmaceuticals, Inc., and owns equity in the company. Mariano Volpacchio: none to declare. Funding assistance for the preparation of this manuscript was provided by Alexion Pharmaceuticals, Inc.

\section{Acknowledgements}

We thank Mark Hughes, PhD, and Shannon Davis of Infusion

Communications for their writing and editorial assistance with this manuscript, which was funded by Alexion Pharmaceuticals, Inc.

\section{Author details}

'División Hematología, Hospital de Clínicas "José de San Martin", Av. Córdoba 2351 (C1120AAR) Ciudad Autónoma de Buenos Aires, 5950-8000 Argentina. 2Departamento de Medicina, Hospital de Clínicas "José de San Martin", Av. Córdoba 2351 (C1120AAR) Ciudad Autónoma de Buenos Aires, 5950-8000, Argentina. ${ }^{3}$ Diagnóstico por Imágenes, Hospital de Clínicas "José de San Martin", Av. Córdoba 2351 (C1120AAR) Ciudad Autónoma de Buenos Aires, 5950-8000, Argentina. ${ }^{4}$ Alexion Pharmaceuticals, Inc., 352 Knotter Drive, Cheshire, CT 06410, USA.

Received: 17 July 2012 Accepted: 23 August 2012 Published: 6 September 2012

\section{References}

1. Weitz IC: Thrombosis in patients with paroxysmal nocturnal hemoglobinuria. Semin Thromb Hemost 2011, 37:315-321.

2. Hillmen P, Lewis SM, Bessler M, Luzzatto L, Dacie JV: Natural history of paroxysmal nocturnal hemoglobinuria. N Engl J Med 1995, 333:1253-1258.

3. Hillmen P, Muus P, Dührsen U, Risitano AM, Schubert J, Luzzatto L, Schrezenmeier H, Szer J, Brodsky RA, Hill A, Socié G, Bessler M, Rollins SA, Bell L, Rother RP, Young NS: Effect of the complement inhibitor eculizumab on thromboembolism in patients with paroxysmal nocturnal hemoglobinuria. Blood 2007, 110:4123-4128.

4. Socié G, Mary JY, de Gramont A, Rio B, Leporrier M, Rose C, Heudier P, Rochant H, Cahn JY, Gluckman E: Paroxysmal nocturnal haemoglobinuria: long-term follow-up and prognostic factors. French Society of Haematology. Lancet 1996, 348:573-577.

5. de Latour RP, Mary JY, Salanoubat C, Terriou L, Etienne G, Mohty M, Roth S, de Guibert S, Maury S, Cahn JY, Socié G; French Society of Hematology; French Association of Young Hematologists: Paroxysmal nocturnal hemoglobinuria: natural history of disease subcategories. Blood 2008, 112:3099-3106.

6. Kelly RJ, Hill A, Arnold LM, Brooksbank GL, Richards SJ, Cullen M, Mitchell LD, Cohen DR, Gregory WM, Hillmen P: Long-term treatment with eculizumab in paroxysmal nocturnal hemoglobinuria: sustained efficacy and improved survival. Blood 2011, 117:6786-6792.

7. Plessier A, Sibert A, Consigny Y, Hakime A, Zappa M, Denninger MH, Condat B, Farges O, Chagneau C, de Ledinghen V, Francoz C, Sauvanet A, Vilgrain V, Belghiti J, Durand F, Valla D: Aiming at minimal invasiveness as a therapeutic strategy for Budd-Chiari syndrome. Hepatology 2006, 44:1308-1316.

8. Nishimura J, Kanakura Y, Ware RE, Shichishima T, Nakakuma H, Ninomiya $H$, Decastro CM, Hall S, Kanamaru A, Sullivan KM, Mizoguchi H, Omine M, Kinoshita T, Rosse WF: Clinical course and flow cytometric analysis of paroxysmal nocturnal hemoglobinuria in the United States and Japan. Medicine (Baltimore) 2004, 83:193-207.

9. de Latour RP, Schrezenmeier H, Bacigalupo A, Blaise D, de Souza CA, Vigouroux S, Willemze R, Terriou L, Tichelli A, Mohty M, de Guibert S, Marsh JCW, Passweg J, Mary JY, Socie G: Allogeneic hematopoietic stem cell transplantation in paroxysmal nocturnal hemoglobinuria. Haematologica 2012. doi:10.3324/haematol.2012.062828. Epub ahead of print.

10. Singer AL, Locke JE, Stewart ZA, Lonze BE, Hamilton JP, Scudiere JR, Anders RA, Rother RP, Brodsky RA, Cameron AM: Successful liver transplantation for Budd-Chiari syndrome in a patient with paroxysmal nocturnal hemoglobinuria treated with the anti-complement antibody eculizumab. Liver Transp/ 2009, 15:540-543.

11. Hillmen P, Young NS, Schubert J, Brodsky RA, Socié G, Muus P, Röth A, Szer J, Elebute MO, Nakamura R, Browne P, Risitano AM, Hill A, Schrezenmeier $H$, Fu CL, Maciejewski J, Rollins SA, Mojcik CF, Rother RP, Luzzatto L: The complement inhibitor eculizumab in paroxysmal nocturnal hemoglobinuria. N Engl J Med 2006, 355:1233-1243.

12. Brodsky RA, Young NS, Antonioli E, Risitano AM, Schrezenmeier H, Schubert J, Gaya A, Coyle L, de Castro C, Fu CL, Maciejewski JP, Bessler M, Kroon HA, Rother RP, Hillmen P: Multicenter phase 3 study of the complement inhibitor eculizumab for the treatment of patients with paroxysmal nocturnal hemoglobinuria. Blood 2008, 111:1840-1847.

13. Hillmen P, Risitano A, Schrezenmeier H, Schubert J, Maciejewski J, Dührsen $U$, Muus P, Szer J, de Castro C, Socié G, Brodsky A: Long-term outcomes in patients with paroxysmal nocturnal hemoglobinuria $(\mathrm{PNH})$ with sustained eculizumab treatment [abstract]. Haematologica 2011, 96(Suppl 2):105.

14. Hillmen P, Elebute M, Kelly R, Urbano-Ispizua A, Hill A, Rother RP, Khursigara $\mathrm{G}$, Fu CL, Omine M, Browne P, Rosse W: Long-term effect of the complement inhibitor eculizumab on kidney function in patients with paroxysmal nocturnal hemoglobinuria. Am J Hematol 2010, 85:553-559.

15. Hill A, Rother RP, Wang X, Morris SM Jr, Quinn-Senger K, Kelly R, Richards SJ, Bessler M, Bell L, Hillmen P, Gladwin MT: Effect of eculizumab on haemolysis-associated nitric oxide depletion, dyspnoea, and measures of pulmonary hypertension in patients with paroxysmal nocturnal haemoglobinuria. Br J Haematol 2010, 149:414-425.

16. Markiewski MM, Lambris JD: The role of complement in inflammatory diseases from behind the scenes into the spotlight. Am J Pathol 2007, 171:715-727. 
17. Zipfel PF, Skerka C: Complement regulators and inhibitory proteins. Nat Rev Immunol 2009, 9:729-740.

18. Rother RP, Bell L, Hillmen P, Gladwin MT: The clinical sequelae of intravascular hemolysis and extracellular plasma hemoglobin: a novel mechanism of human disease. JAMA 2005, 293:1653-1662.

19. Socié G, Muus P, Schrezenmeier H, Hochsmann B, Maciejewski JP, Weitz IC Hill A, Bessler M, Risitano AM: Terminal complement inhibitor Eculizumab improves complement-mediated platelet consumption and thrombocytopenia in patients with paroxysmal nocturnal hemoglobinuria (PNH) [abstract]. Blood 2009, 114:4030.

20. Hoekstra J, Leebeek FW, Plessier A, Raffa S, Darwish Murad S, Heller J, Hadengue A, Chagneau C, Elias E, Primignani M, Garcia-Pagan JC, Valla DC, Janssen HL; European Network for Vascular Disorders of the Liver: Paroxysmal nocturnal hemoglobinuria in Budd-Chiari syndrome: findings from a cohort study. J Hepatol 2009, 51:696-706.

doi:10.1186/2162-3619-1-26

Cite this article as: Brodsky et al: Eculizumab in paroxysmal nocturnal hemoglobinuria with Budd-Chiari syndrome progressing despite anticoagulation. Experimental Hematology \& Oncology 2012 1:26.

\section{Submit your next manuscript to BioMed Central and take full advantage of:}

- Convenient online submission

- Thorough peer review

- No space constraints or color figure charges

- Immediate publication on acceptance

- Inclusion in PubMed, CAS, Scopus and Google Scholar

- Research which is freely available for redistribution 